\title{
Launching our first expert panel report
}

\author{
Our expert panel on urban science has now delivered its much-awaited report, following more than a year of lively \\ and intensive debate.
}

$\mathrm{N}$ ature Sustainability launched in January this year with the remit of providing insights into the interaction between people and the natural world ${ }^{1}$ and an explicit proposition to the broad community of sustainability scholars and practitioners - one fitting for an outlet that proactively stimulates pioneering research on the most pressing sustainability challenges of our time, while encouraging lively, relevant debates within and beyond academia. Finding innovative ways to engage the community and respond to its evolving needs has been at the core of our editorial strategy. We started our engagement journey before the journal's launch. In April 2017, we convened the first Nature Sustainability expert panel on urban science. It was set up as collaboration with University College London (www.cityleadership.net/naturesustainability-panel). Focussed on urban science-policy interactions in the context of global sustainability, the panel contributes to the ongoing discussion on the role of cities in shaping our future. This discussion is seen in recent multilateral initiatives, such as the 2030 Sustainable Development Agenda ${ }^{2}$ and the New Urban Agenda ${ }^{3}$, launched in 2015 and 2016 (respectively) by the United Nations. Agreement about the central role of cities in achieving a sustainable future has nevertheless come with concerns about the state of urban science and its limited policy engagement. The Nature Sustainability expert panel, an independent and international effort, responds to such concerns by assessing the state of the urban science-policy interface for global sustainability, and proposes more effective ways to develop policy-engaged urban scholarship.

In order to convene the panel, Nature Sustainability worked closely with three scholars, Michele Acuto, Susan Parnell and Karen Seto. They reached out to the broad community of experts with a focus on global urban policy. The response from the community was warm and enthusiastic, and we ended up with a panel of 29 leading scholars on urban issues. Between them, they cover a wide variety of natural and social science disciplines in addition to humanities, architecture and planning, engineering, computer science and environmental science, and they represent institutions from most continents. The

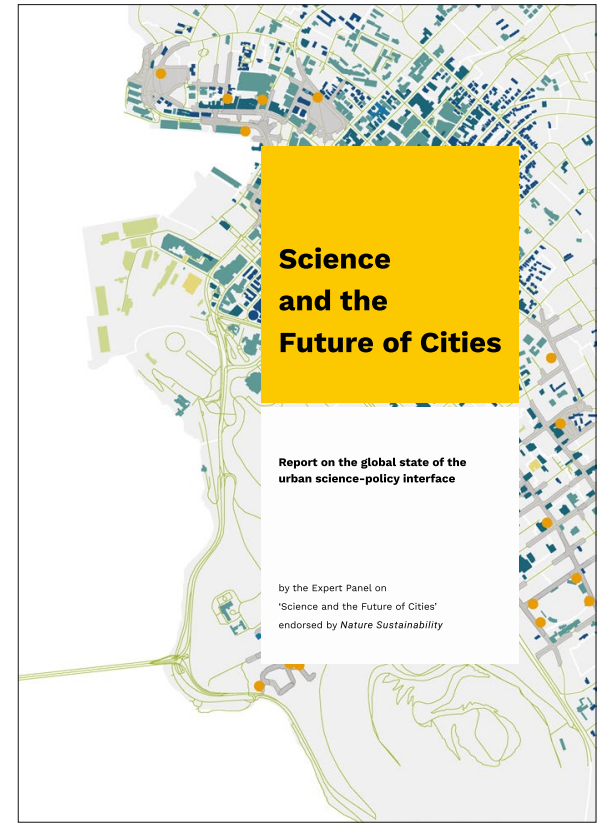

Credit: AUSTRALIAN URBAN RESEARCH INFRASTRUCTURE NETWORK, UNIVERSITY OF MELBOURNE, AUSTRALIA (2018).

panellists met in London in July 2017 for the first time, joined by Nature Sustainability Editors. After the first meeting, the discussions continued with roundtables at the Nature campus in London, the African Centre for Cities in Cape Town and the World Urban Forum in Kuala Lumpur, in 2017 and 2018. Early on, some clear and firm discussion points emerged that defined the operating framework of the panel's review exercise. We captured them in a Comment authored by the three convening experts, published in our January issue ${ }^{4}$. The extended and intensive engagement has now reached a milestone: the launch of the expert panel's report ${ }^{5}$ that we at Nature Sustainability so happily endorse. 'Science and the Future of Cities' highlights the panel's work on the current challenges of the urban science-policy interface and introduces recommendations to strengthen the use of scientific urban research in policy. Our hope is that the synthesis and reflections presented in the report will stimulate broader discussions and widen engagement across a large number of scholars and practitioners with an interest in cities and sustainability.
While this Editorial was being written, plans were being firmed up for a new expert panel to launch early in 2019. We intend to promote this kind of regular interaction and debate on key themes relevant to our editorial scope and mission. We have also enjoyed the multiple side discussions that the initiative has generated so far, and have nurtured some of the ideas that emerged as a result. However, we are conscious of some inherent limitations of this approach and feel it important to reflect on the project objectively. We convened the expert panel as a proactive way of engaging a community of interest, urban scholars, with a need that we could help to fulfil - stimulating new thinking and action to enhance the way that urban science engages with policy. However, we were conscious all the way through that, given the scale and diversity of the research community involved, aiming to convene a fully representative sample of experts would have been overly ambitious. As is highlighted explicitly in the report, it is therefore important to emphasize that no claims to international authority are made by the panellists. In selecting the members of the expert panel, the Editors and collaborating institutions attempted to reflect diverse disciplinary and geographical perspectives. But, the views expressed in the report do not fully reflect the breadth and depth of urban thinking in academic circles globally.

On balance, we see the 'expert panel' concept as a proactive way of fostering debate and intellectual efforts where they are most needed. We will continue to promote this initiative on urgent sustainability themes, engaging with the relevant communities, and we expect to see the expert panels we endorse evolving with the journal remit and the needs of the diverse groups of scholars who we serve.

Published online: 14 December 2018 https://doi.org/10.1038/s41893-018-0209-7

\footnotetext{
References

1. Nat. Sustain. 1, 1 (2018)

2. Transforming our World: the 2030 Agenda for Sustainable Development (United Nations, 2015)

3. Habitat III New Urban Agenda (UN-Habitat, 2017); http://habitat3.org/wp-content/uploads/NUA-English.pdf

4. Acuto, M., Parnell, S. \& Seto, K. C. Nat. Sustain. 1, 2-4 (2018).

5. Science and the Future of Cities (International Expert Panel on Science and the Future of Cities, 2018); https://www.nature.com/ natsustain/expertpanels
} 